\title{
On the Postmodern Narrative Techniques in Slaughterhouse-Five
}

\author{
Jing Shi \\ School of English Language, Shanghai International Studies University, Shanghai, China; \\ School of Foreign Languages, Shanghai Institute of Technology, Shanghai, China
}

\begin{abstract}
Kurt Vonnegut is admitted as a great master of postmodern writer. Vonnegut's success is mainly attributed to his unique narrative approaches, various expressive methods and dramatic artistic effects. The application of metafiction is particularly obvious and significant in his novels. Slaughterhouse-Five is one of typical examples of the successful adoption of metafiction. The metafiction of Vonnegut's style, applied in Slaughterhouse-Five, shows itself in three distinctive approaches-non-linear narrative, collage and parody. Based on postmodern narrative theory, the application of these three distinctive narrative techniques will be analyzed in details in this thesis. The analysis mainly includes the reasons why they are applied in the novel and the functions how they work. The paper is mainly divided into five parts. Relevant information of Vonnegut, postmodern metafiction and previous researches are introduced in the first chapter. After getting better acquainted with basic knowledge, three narrative methods of Vonnegut's metafiction including nonlinear narrative, collage and parody are separately and detailedly analyzed in the following three chapters. Every method applied in the novel deepens the anti-war theme, and then exposes war's evilness and absurdity further. Finally, the last part is a conclusion which is an emphasis on effects of Vonnegut's unique narrative techniques.
\end{abstract}

Index Terms-Kurt Vonnegut, Slaughterhouse-Five, non-linear narrative, collage, parody

\section{INTRODUCTION}

Kurt Vonnegut's masterpiece Slaughterhouse-Five is a typical metafiction with many distinctive narrative techniques. To get better acquainted with Vonnegut's unique postmodern narrative techniques, knowing enough knowledge of life experience of the author and historical and cultural background of his time is necessary. Some basic information of Vonnegut, his novels, postmodern metafication and relevant researches will be introduced in this part.

\section{A. Kurt Vonnegut and Slaughterhouse-Five}

Kurt Vonnegut (1922-2007) was one of the most far-reaching influential American writers in the 20th centuries. Vonnegut was admitted as a great master of postmodern writer. He was skilled in writing miserable stories in comic form and sneering at the crazy society in the face of despair and disaster. He was also known for his distinctive writing methods. His narrative techniques possessed various forms, such as parody, collage and so on. For instance, his novels always consisted of abundant fragmentized pieces which included quotations of wonderful poems, humorous doggerels, as well as indecent quartettes. Additionally, majority of his works were a mixture of autobiography and fiction. Vonnegut used to experience a period of heartrending army life as an American prisoner during World War II. He was imprisoned in Dresden, witnessing its perishment, which had a profound influence on his later works as a survival from Dresden Bombing. The most typical novel was Slaughterhouse-Five (1969). Apart from Slaughterhouse-Five, Cat's Cradle (1963), Breakfast of Champions (1973), Jailbird (1979), Timequake (1997) all vividly showed unique imagination and special artful charm. Besides novels, Vonnegut also produced screenplays, essays and short stories. However, as for the thesis, narrative methods in the novel are attached more importance to.

Slaughterhouse-Five is also called The Children's Crusade: a Duty-Dance with Death. Vonnegut depicted a leading figure, Billy Pilgrim, who also experienced the firebombing of Dresden as a prisoner, as well as a survivor of the awful slaughter in the novel. Therefore, this novel was deemed to Vonnegut's autobiography by some scholars. An absurd journey, or more accurately, an almost frantic time travel of the Protagonist Billy Pilgrim was described in the novel. Vonnegut skillfully created a novel about the time travel of Billy who shared the identical traumatic experience in WWII with that of Vonnegut. Some deviant narrative methods flourished in the novel. Firstly, the author adopted deftly non-linear narrative strategy to narrate Billy's leaping life experience including the war-time prison in Dresden, the after-war home in America, and the Utopian Planet Tralfamadore through frequently shifted perspective and chaotic time-space view to expose war's absurdity and cruelty. What's more, the author also cited quantities of fragmental passages or sentences from different sources to reveal the nature of war in an indirect way. Except for these two distinctive narrative features, Vonnegut also created a new text on the basis of imitating some original religious stories, such as The Pilgrim Progress (1678) of John Bunyan in Slaughterhouse-Five. Then he also applied the new text to an inappropriate or a totally contrary context to improve the effect of irony. 
All in all, these features are the unique manifestation of non-linear narrative, collage and parody which all originated from postmodern metafiction. These distinctive narrative methods make the novel express its themes incisively and vividly.

\section{B. Postmodernism and Metafiction}

Postmodern writers use various postmodern narrative techniques in the boldest attempt for reference. Especially, the application of Metafiction is ubiquitous in the postmodern novels. "Meta" originally meant "after", serving as a prefix, in Greek. After the long history of development of languages, gradually Meta gained its new meaning "originality". Metafiction came into people's visions in 1960s, and then came to light. Afterwards, metafiction put a new soul into postmodern culture, especially postmodern novels. As a result, postmodern writers usually attempt to wield metafiction to express their real feelings about the world and search for truths at a crucial crossroads of fiction and reality.

As Patricia Waugh said, "Metafiction is a term given to fictional writing which self-consciously and systematically draws attention to its status as an artifact in order to pose questions about the relationship between fiction and reality. In providing a critique of their own methods of construction, such writings not only examine the fundamental structures of narrative fiction, they also explore the possible fictionality of the world outside the literary fictional text" (Waugh, 1984, p. 2). In other words, postmodern novels are involved with the deconstruction and overthrow of traditional novels in their forms and narrative methods. Therefore, postmodern novels are also known as anti-traditional novels.

Traditional novels focus on characters, incidents or something related to the content of a novel. On the contrary, metafiction attaches more importance to the process how an author create a novel. For one thing, metafiction always prefers to directly inform readers that its author is making up a story. For another, the narrator always occurs in the novel in various capacities, even as the close company of the protagonist. In a word, the distinctive features of a metafiction show primarily in two aspects: one is elucidation of creation process; the other is exposure of the author's identification. Both two features offer a chance to explore the relation between fiction and reality. But Vonnegut made a breakthrough over initial metafiction in his own way.

The meta-fiction of Vonnegut style, applied in Slaughterhouse-Five, shows itself in three distinctive approachesnon-linear narrative, collage and parody. Each method has relatively distinctive features. Non-linear narrative does not follow chronological order of events, and behaves itself in an abnormal way, such as chaotic space-time view or transformation of personal perspectives. Collage means mingling various original parts of other materials and recombining them, then taking shape in a new text. Parody means that one novel imitates deliberately other novels' contents and forms to apply to an inappropriate and even converse context, so that the novel can realize its irony and criticism. As Simon Dentith said, "the contention is simply this: that parody is one of the many forms of intertextual allusion out of which texts are produced. In this sense, parody forms part of a range of cultural practices, which allude, with deliberate evaluative intonation, to precursor texts" (Dentith, 2001, p.16).

In conclusion, the application of these three methods adds energy and vitality to Slaughterhouse-Five. They play active roles in writing process of the novel. For Vonnegut, a simple statement of the firebombing of Dresden could hardly express the author's soreness and hatred. Additionally, there is no logic for a real war. As a consequence, Vonnegut chose metafiction as an "architectural blueprint", using all these approaches to separate his novel from the regular restricted by the cause-effect relation, chronological order and narrative completeness. In combination with the example of Slaughterhouse-Five, readers may find a shortcut to understand the theme of novel and the structure of meta-fiction. Their unusual magic to broaden readers' horizon will be specifically analyzed in the following parts in Slaughterhouse-Five.

\section{NON-LINEAR NARRATIVES IN SLAUGHTERHOUSE-FIVE}

Based on all above information, Vonnegut had to search for a new access to reflect the cruelty of the Second World War to avoid turning the novel into a traditional reminiscence. However, traditional linear narrative technique wouldn't reach this special effect. Traditional realistic novel usually develop a story following a linear narrative. One of distinctive features of linear narrative is that the narrative time and the time line of a story are exactly same and synchronized. This narrative method aims at depicting and reproducing a story according to the original development of the story whether in time or space aspect. Under the circumstances, readers are passive to perceive, and even accept some truths that the author wants readers to know. However, non-linear narrative gives reader a new way to appreciate novels. Another typical feature of linear narrative is that the narration of a novel follows some kind of logical sequence, such as chronological order, spatial transference, and cause-effect relation and so on. Although those sequences sometimes are reversed, like flashback, readers can figure out the exact order that the novel abides by finally. Additionally, traditional novel usually takes the first perspective or the third perspective to tell a story under normal conditions. Otherwise, non-linear narrative has no specifically logical order to comply with. It always describes stories with a multi-angle of view or an intervened and leaping narrative space-time view. A novel can reflect itself on a deeper level by taking non-linear narrative. So Vonnegut created a seemed rough-and-tumble text by taking full advantage of non-linear narrative to express human beings' confuse and helplessness in the face of war. Therefore, the reason of application of non-linear narrative and its function will be focused in this chapter.

\section{A. The Reason of Adoption of Non-linear Narratives}


Vonnegut took non-linear narrative for a specific reason, and the reason exactly caused non-linear narrative in turn. In general, Vonnegut's post-war traumas mainly engendered the adoption of non-linear narratives. In order to understand the narrative, readers must get a better understanding of his mental traumas caused by the Dresden Bombing.

The tragedy of Hiroshima is universally known, while Dresden's secret is rarely acquainted by people. Dresden was as city with cultural heritages, and it has no war industries. Frederick Taylor also wrote that the city was largely undefended. People rarely anticipated the occurrence of the bombing. Nevertheless, the bombing still occurred. In the Bombing of Dresden in February 1945, around 25,000 people died, and over 1,600 acres of the city Dresden were destroyed by British and US Air Forces during three days. Comparing with atomic bombing of Hiroshima, Dresden bombing is more brutal and ruthless.

Based on the misery of Dresden, Vonnegut used to intentionally make a special introduction of Slaughterhouse-Five, describing as "The Dresden atrocity, tremendously expensive and meticulously planned, was so meaningless; finally, that only one person on the entire planet got any benefit from it. I am that person. I wrote this book, which earned a lot of money for me and made my reputation, such as it is. One way or another, I got two or three dollars for every person killed. Some business I'm in" (Vonnegut, 1981, p. 302). He witnessed the occurrence of the bombing. Therefore, his comments about the war were more authentic and credible than other reviews. However, the bombing left him no "benefit", but everlasting pain. This unavoidable sorrow laid a foundation of his non-linear narrative.

According to the above information, the reason why Vonnegut adopted non-linear narrative method cannot be separated from his experience as a soldier. The Dresden Bombing was an indelible pain in his memory. Recollecting his memory in a reasonable and sequential way seemed to be hard for a man who witnessed an inhumane and senseless slaughter. As Vonnegut said in the novel, "I don't think this book is ever going to be finished. I must have written five thousand pages by now, and thrown them all away" (Vonnegut, 1969, p. 7). He was even not sure whether he could finish it or not. That's what war left him, an unhealed war trauma. A series of post-traumatic stress disorders caused by war trauma are the main reasons why Vonnegut chose non-linear narrative. In other words, this is a kind of "Dresden complex".

The term "trauma", as the Oxford English Dictionary indicates, originally means "a wound, or external bodily injury in general", but it can also signify "a psychic injury, especially one caused by emotional shock, the memory of which is repressed and unhealed" (1989, p. 1252). Originally, the word "trauma" means some physical wounds. Afterwards, its meaning broadens as a mental disease caused by some emotional stimulus. Sigmund Freud is the forerunner in trauma studies. In terms of Freud, the definition of trauma, "involves a radical rethinking of the causality and temporality of memory. The traumatic incident is not fully acknowledged at the time that it occurs and only becomes an event at some later point of intense emotional crisis" (Whitehead, 2004, p. 6). In 1980, psychological responses after trauma was officially defined as post-traumatic stress disorder in magazine, named Diagnostic and Statistical Manual of Mental Disorders. Therefore, Vonnegut stated in his novel, "People aren't supposed to look back. I'm certainly not going to do it anymore" (Vonnegut, 1969, p.11). He was unwilling to look back, and even afraid to recollecting the slaughter. That's one of the post-traumatic stress disorders-refusing to reminiscence. Another one is memory disorders. Vonnegut generated a lapse in memory and kept repeating some content again and again, such as narrator's name. Therefore, it took numerous bloods, toil tears and sweat for Vonnegut to write a book about the massacre under his "Dresden complex". For him, the war was what he mentioned in Slaughterhouse-Five, “And, even if wars didn't keep coming like glaciers, there would still be plain old death" (Vonnegut, 1969, p.3).

Vonnegut, "an abnormal narrator", suffering from some post-war traumatic stress disorders, could only express him in such a turbid and clueless thought. The protagonist Billy, same as Vonnegut, a survivor from the Dresden Bombing, could not acted as a normal person, addicting to time travel between the reality and the illusion. All in all, to accurately reflect Billy's post-traumatic stress disorders or the author's own psychological state, Vonnegut took non-linear narrative as a vital tool to uncover what the war brought to human beings, and to reveal his detestation to aggressive wars.

\section{B. Transformation of Perspectives}

In Slaughterhouse-Five, Vonnegut adopted a fire-new narrative mode to show his readers a distinctive anti-war novel. Vonnegut made a great difference in the comprehensions of readers, leading them to understand his war experience. As Gérard Genette evaluated, "Vonnegut integrated the author, the character and the narrator, which broke away the regulation of narration, not only its traditional structure, but also its logic of narration" (Genette, 1990, p.7). Vonnegut's self-discussion and self-reference made a breakthrough in traditional novels. Vonnegut, as an author, a character and a narrator, separately intervened the narration of the novel. He worked as a "narrator" to tell readers Billy's chaotic time travel appearing both in the novel and out of the novel. Meanwhile, he purposely placed himself into the first chapter and the last chapter, becoming a character in the novel.

Firstly, readers could easily find that Vonnegut's self-introduction consisting of his name, the places where he had been and the preparation for the novel, which was placed below his signature in the title page of Slaughterhouse-Five. In other words, Vonnegut as the author appeared in the novel from the title page. Following on, the author Vonnegut came up in the first chapter. However, he had already depicted the tragedy of Dresden to his readers in a character tone to his readers, 
"I would hate to tell you what this lousy little book cost me in money and anxiety and time. When I got home from the Second World War twenty-three years ago, I thought it would be easy for me to write about the destruction of Dresden, since all I would have to do would be to report what I had seen. And I thought, too, that it would be a masterpiece or at least make me a lot of money, since the subject was so big. But not many words about Dresden came from my mind then-not" (Vonnegut, 1969, p.2).

The author frankly announced that he attempted to write a book about his experience in the Second World War, but he suddenly realized that he could hardly express what the war brought. In the novel, the author also said: "It is so short and jumbled and jangled, Sam, because there is nothing intelligent to say about a massacre. Everybody is supposed to be dead, to never say anything or want anything ever again. Everything is supposed to be very quiet after a massacre, and it always is, except for the birds". Except for the Dresden Bombing, the author's life experience was totally shown to readers.

Therefore, it might confuse readers that "the Vonnegut" appearing in the first chapter and the real author Vonnegut of this novel seemed to be the same person for their surprisingly similar life experience. For example, both of them experienced a period of heartrending army life as an American prisoner during World War II. They were imprisoned in Dresden witnessing its perish personally, which had a profound influence on their later works as survivors from Dresden Bombing. In fact, "the Vonnegut" in the novel was not the real author of this novel any longer. As an author, Vonnegut gave clear-cut clues at the end of the first chapter, telling readers that: "I've finished my war book now. The next one I write is going to be fun" (Vonnegut, 1969, p.10). Following on, he unveiled the beginning and ending of Slaughterhouse-Five. As Neil D. Isaacs pointed out that: "Slaughterhouse-Five is a book about the writing of the book" (Isaacs, 1973, pp.122-131). So did the last chapter. In conclusion, all the clear publicly-available content that the author revealed to readers aims at exposing his identity as an author, confusing readers that the novel is fictional.

Secondly, Vonnegut began to tell a story from the second chapter. The protagonist Billy and his absurd time travel were shown to readers. Meanwhile, the author Vonnegut became the first-person narrator of the novel. Vonnegut began to describe what happened to Billy's life to his real readers in detail. And he as a character in the novel disappeared in the following parts. Nevertheless, Vonnegut's voice as a character keeping coming out in the novel till the end of the novel: "It would make a good epitaph for Billy Pilgrim and for me, too...That was I. That was me. That was the author of this book" (Vonnegut, 1969, pp.55-56). He as a character reminded readers to carefully distinguish between "the narrator Vonnegut" and "the character Vonnegut" from time to time. Thus, the fictional meta-narrative created by Vonnegut in the beginning of the novel was dispelled. It is not hard to see that Vonnegut applied an omniscient and omnipresent mode of entire-focalization to describe Billy's miserable experience in the Dresden Bombing and his successful business life after war. Although the war ended, Billy could not escape from the dusty cloud of the war. Meanwhile, Vonnegut as a fictional character made a full explanation about the novel, especially in the first and last chapter.

All in all, no matter what a role Vonnegut played in and out of the novel, an author, a narrator or a character, he retrospected some important stages in Billy's life in an aloof and cynical tone. Especially, the simple sentence "so it goes" which occurred more than a-hundred times. And readers could feel Vonnegut's indifference to what happened to the surrounding. Every time it turned up, its meaning was deepened, and finally it became a harbinger of death. However, the cruelty of war and the loss of humanity were vividly exposed to readers by his unconcerned attitude. In slaughterhouse-five, Vonnegut expressed his own opinions and bewilderment about the world and human from the perspectives of the novel's narrator and character. Vonnegut combined himself with the novel's character through the transformation of perspectives, which was regarded as an innovation in narrative perspective. Vonnegut established unique tension of metafiction between construction of fictionality and deconstructing of it. All in all, the transformation of perspectives not only shows Vonnegut's masterly narrative skills, but also deepens the novel's themes-uncovering the miserable experience of some people involved in the Second World War to reveal wars' absurdity and abnormality in black humor technique.

\section{Chaotic Time-space Views}

Chaotic time-space view is another distinct feature of Vonnegut's non-linear narrative. The tangled time and space are also called fragments of time and space. The arrangement of time and space is extremely complicated in Slaughterhouse-Five. The narrative time constantly switches from the past to the present; the narrative space shifts from the earth to the planet Tralfamadore. He created a fire-new narrative mode, making a combination of reality and imagination, and synchrony and diachrony. The art of fragments could be apparently perceived through the whole novel. As James Lundquist pointed out that "Vonnegut strives to reveal new viewpoints in somewhat the same way the theory of relativity broke through the concepts of absolute space and time" (Lundquist, 1976, p.71) in his novel. At first, readers maybe feel confused when reading the novel. Gradually, readers might find the author's deep intension in a higher and broader perspective eventually.

Firstly, the tangled narrative time is a distinguishing feature of slaughterhouse-five. In the beginning, Vonnegut made it clear that "Billy Pilgrim has come unstuck in time" (Vonnegut, 1969, p.12). Then through description of Billy's symptom for losing in time, he gradually exposed the structure of fragmental time and space. After a piece of brief explanation, "Billy is spastic in time, has no control over where he is going next, and the trips aren't necessarily fun. He is a constant state of stage fright, he says, because he never knows what part of his life he is going to have to act in 
next" (Vonnegut, 1969, p.12), interlaced time extended immediately. Vonnegut "mixedly loaded" Billy's life during a long period from 1922 to 1976. Fragmental slice of life constantly switched between the war life and after war life without control. The memories of the author or Billy about war were impaired. On Vonnegut's part, there was no need to follow the traditional sense of time or one direction from past to future. Some other scholars also supported him, for instance, "twenty years after the publication of SF, theoretical physicists like Stephen F. Hawking are becoming more convinced that there is no reason why under some circumstances the arrow of time might point from future to past rather than from past to future" (Xie, 2009, p.24). This kind of time view brought the past and the present in the same level. In fact, the author wanted to convey Billy's obsession in war's trauma, indifference to current life and hopelessness to future. Billy returned to the war so many times from his current life. That was because he could not help himself to recollect the war. He could not escape from what the war left to him: a serious mental disease with a physical symptom - memory disorders. All in all, Vonnegut attempted to reveal war's cruelty through the disordered time.

Apart from the chaotic time, tangled space is also deviant from traditional narration. The chaotic space also offered an opportunity to make a contrast between life on earth and life on Tralfamadore where "there is no beginning, no middle, no end, no suspense, no moral, no causes, no effects" (Vonnegut, 1969, p.88) far away from earth about 446,120,000,000,000,000 miles, reflecting a distinct death concept. As Vonnegut mentioned that, "The most important thing I learned on Tralfamadore was that when a person dies he only appears to die. He is still very much alive in the past, so it is very silly for people to cry at his funeral. All moments, past, present and future, always have existed, always will exist" (Vonnegut, 1969, p.13). Vonnegut created an imaginary planet-Tralfamadore, so that Billy could make his pungent complaints about war and death on the planet Tralfamadore. Nevertheless, Vonnegut's real purposes of creating a fictional planet were not to simply create an illusion, but to expose some truths. He conveyed a new concept of death that death was a way to renew ourselves by dint of Billy's experience on Tralfamadore. From this viewpoint, readers might guess that Tralfamadore was an ideal living environment for Billy. In this sense, Vonnegut created the ideal planet to express his attitude to death and hatred to war indirectly. Just like William Rodney Allen said that, "Vonnegut hopes to push the reader's perceptual horizon as far as he can toward infinity-toward the union of all time and all space" (Vonnegut, 1991, p.77).

In conclusion, the chaotic time-space view provides readers a fire-new perspective to get a better understanding of the novel. This perspective, for one thing, makes Billy slip the leash from the limitation of time ad space in the earth, totally breaking our original comprehension to time and space to show Billy's serious post-war trauma. For another, it helps Vonnegut to reveal human being's helplessness, despair and frustration to real life. Finally, anti-war theme reaches its climax along with the time travel of Billy.

\section{Collages In Slaughterhouse-Five}

Collage is also one of typical manifestations of Vonnegut's metafiction. Collages are a prevailing trend in Slaughterhouse-Five. Collages consist of the collage of some referenced fragments and that of chaotic contents caused by chaotic time-space view in the novel. Both of the two kinds of collages smash the coherence of the novel, which results in uncertainty of narration. Authors do not give readers any clue about what will happen in the next moment. It makes the content of a novel tanglesome and irrational. Nevertheless, the irrationality and disorder map the confusion of life. So they could better convey people's helplessness and passive acceptance of reality in such "a dementia praecox kingdom".

The former one is chosen to dissect collages of citations in the novel's content in this paper. When one first appreciates it, suddenly he/she feels that the whole novel is made up of odds and ends without the whole beauty. Actually, the application of collages is one of best lines in Slaughterhouse-Five. As mentioned, collage refers to a wide quotation of various materials from different sources. According to the above definition, collages in the novel could be divided mainly into three categories, including official sources, folk cultures, and literary works. Description about a war varies according to different people, different occasions and different sources. Every piece meticulously selected by Vonnegut has his intension. To sum up, materials of the Dresden's Bombing and other massacres involved in the novel add a heavy sense of history, while humorous and ridiculous folk cultures release readers' heavy pressure. These three collages and their special function will be analyzed in the following three parts.

\section{A. Collages of Official Sources}

About the Firebombing of Dresden, Vonnegut did not offer his opinions or materials relevant to the bombing direct. Instead, he borrowed some official sources which mainly refer to a Truman statement and a record of the population in Dresden.

Firstly, he quoted President Harry S. Truman's announcement about the atomic bomb dropped on Hiroshima, "Sixteen hours ago an American airplane dropped one bomb on Hiroshima, an important Japanese Army base. That bomb had more power than 20,000 tons of T.N.T... Let there be no mistake; we shall completely destroy Japan's power to make war. It was to spare-" (Vonnegut, 1969, pp.82-83). These detailed words thoroughly indicated the deadly lethality of atomic and Truman's strong ambition to conquer the whole world, giving too little care to lives of thousands of millions of innocent human beings. Through the citation, the author implicated that human being attempted to 
enslave the entire world at the cost of numerous death. He accused of inhuman ambition at the expense of extinction of mankind, and further condemned that wars wantonly trampled on the value of existence.

Moreover, Vonnegut seemed to unconsciously gain information of Dresden's population when talking with his friend O'Hare. The record said, “On an average, 324,000 new babies are born into the world every day. During that same day, 10,000 persons, in an average, will have starved to death or died from malnutrition. So it goes. In addition, 123,000 persons will die for other reasons..." (Vonnegut, 1969, p.94). To these words, Vonnegut gave his response, "I suppose they will all want dignity" (Vonnegut, 1969, p.94). Whether in the Dresden's bombing or in the atomic bombings of Hiroshima and Nagasaki, wars devoured countless lives. However, dying seemed to be a daily thing, as natural as living. He implied that death is passively and reluctantly inevitable.

Both two pieces of quotation seemed to be irrelevant to the content of the novel. But, actually these official documents made excuses to wage war and made emphasis on the inevitability of death. These citations indirectly reflected Vonnegut's hatred to wars and his despair of survival. The anti-war theme deepens itself further.

\section{B. Collages of Literary Works}

As the proverb goes, "There are a thousand Hamlets in a thousand people's eyes". About the massacre of Dresden, different authors hold different views. Works written by other famous writers about war are frequently cited to expose thoroughly sin of war in Slaughterhouse-Five. Vonnegut recorded the Dresden's Bombing through plentiful direct quotations. He depicted this historical tragedy in a round-about way. Some typical citation will be analyzed detailedly in the next paragraphs.

For instance, during a talk with his friend, Vonnegut mentioned a book named Extraordinary Popular Delusions and the Madness of Crowds (1841), written by Charles Mackay. After Vonnegut said "Mackay had a low opinion of all Crusades", he cited, "History in her solemn page informs us that the Crusaders were but ignorant and savage men, that their motives were those of bigotry unmitigated, and that their pathway was one of blood and rears..." and "Now what was the grand result of all these struggles? Europe expended millions of her treasures and the blood of two million of her people; and a handful of..." (Vonnegut, 1969, p.29). Although Vonnegut did not immediately make his comment on war, this piece of words indicated that he had already taken his stand to war. These phrases, such as "ignorant and savage men" and "the blood of two million of her people", elaborated his contempt to war and pity to victims. Readers still could experience war's depression and sorrow, although Vonnegut did not describe excessively bloody scenes.

For another example, Vonnegut borrowed a little section of Dresden, History, Stage and Gallery (1908), written by Mary Endell. In a sense, war destroyed art, as Mary said: "Now, in 1760, Dresden underwent siege by the Prussians. On the fifteenth of July began the cannonade. The Picture-Gallery took fire... The devastation of Dresden was boundless... Das hat her Feind Gethan" (Vonnegut, 1969, p.9) in the novel. Dresden, a prosperous and cultural city lay in ruins in a trice, which aroused readers' inner sympathy. The devastation of war not only brought massive death, but also demolished human's spiritual civilization - art. Therefore, consequences of war are beyond the imagination, not an individual lost but a true decline of the world.

In summary, every piece of word that the author borrows from others works plays a role in increasing the anti-war effect. Though Vonnegut does not point out that war is cruel and evil, readers could feel angry and abomination to war through descriptions of other excellent scholars. Implicitly and automatically, Vonnegut gets strong resonance from readers finally.

\section{Collages of Folk Cultures and Other Sources}

A large amount of quotation of folk culture is also one of prominent collages. Various Folk cultures mainly consist of quartette, doggerel, prayers and slogans and so on. Apart from these cultures, soldiers' letter is also pasted in the novel. On one hand, those materials remit repression caused by others' works description about war. On the other hand, they aggravate derisiveness to war.

The most typical example is a prayer on Billy's office in the third chapter, which says:

GOD GRANT ME

THE SERENITY TO ACCEPT

THE THINGS I CANNOT CHANGE

COURAGE

TO CHANGE THE THINGS I CAN, AND WISDOM ALWAYS

TO TELL THE

DIFFERENCE (Vonnegut, 1969, p.28).

Every word of this piece of prayer disclosed regrets and helplessness to life. As the prayer said, resignation to fate was a kind of wisdom. That is, struggling against fate is meaningless; and acceptance of death, war or other miseries is the right attitude. After reading, readers might feel the insignificance of human in the face of destiny. In addition, it also reflected that Vonnegut's spirit got caught into desperation after war.

Another typical example is a famous limerick. When Vonnegut felt hard to recollect memories of Dresden, he tried to relieve his anxiety by quoting some folk culture, such as:

There was a young man from Stamboul, 
Who soliloquized thus to his tool,

'You took all my wealth

And you ruined my health,

And now you won't pee, you old fool' (Vonnegut, 1969, p.3).

In spite of obsession with slaughter of Dresden, he could not make a book of Dresden for after-war trauma. Recollecting his memories of the war was killing him and leading him to nervous breakdowns. And he could not get rid of torment of the war. This dirty and vulgar limerick was a temporary relief to his sad emotion. Meanwhile, readers also could take a breath from depression in virtue of it.

Another intentional collage is a soldiers' letter, which says:

"Derby was imagining letters to home, his lips working tremulously. Dear Margaret-We are leaving for Dresden today. Don t worry. It will never be bombed. It is an open city. There was an election at noon, and guess what? And so on" (Vonnegut, 1969, p.66).

What a silly idea! Soldiers believed safety of Dresden and fancied going home, only to occur a dispiteous bombing without expectation. For one thing, the letter arouses readers' sympathy to those soldiers and awakened resentment to war. For another thing, the letter bitingly denounces brutality of war and unprediction of future.

To sum up, folk cultures differ from other sources of citation, and they have two major functions. On one hand, these diverse cultures relieve readers' depression when they read the novel. On the other hand, Vonnegut ingeniously utilizes these quotations to create black humor to satire wickedness of war.

\section{Parodies in Slaughterhouse-Five}

Parody is widely applied in post-modern novels as one of techniques of metafiction. Postmodern novels overthrow traditional novels by wielding parodies to convey some worries and anxieties. Parody owns far-reaching imitative objects, such as a sentence, a text, a classic work, and even an already existed historical event. Simply speaking, parody means borrowing other works to realize its effect of irony and scoff. Chris Baldick said that parody was "a mocking imitation of the style of a literary work or works, ridiculing the stylistic habits of an author or school by exaggerated mimicry. Parody is related to burlesque in its application of serious styles to ridiculous subjects, to satire in its punishment of eccentricities, and even to criticism in its analysis of style" (Vonnegut, 1996, p.161). Parodic targets in Slaughterhouse-Five are principally constitutive of Pilgrim's Progress, Adam and Eve in Eden and Jesus' Prediction of Death. Parodies make pungent contrasts between the parodic objects and the parodied texts to achieve a comical effect and convey special messages.

\section{A. The Pilgrim's Progress: Billy's Time Travel}

The Pilgrim's Progress (1678) written by John Bunyan, is one of the most remarkable religious novel. One part of the novel is about Christian's journey to celestial city, and the other part tells the travel of Christian's wife - Christina and her children to celestial city. The allegorical tale depicts the leading character Christian's spiritual journey and struggles from unbelief and sinfulness to salvation and glory. Careful readers could find that Billy Pilgrim in the novel shares the same word "Pilgrim" with the Pilgrim's Progress. It is not a coincidence, but deliberation. In fact, Vonnegut skillfully uses the word "Pilgrim" to shorten the distance between Christian and Billy.

However, unlike Christian, Billy Pilgrim had a journey to an exoplanet-Tralfamadore to look for ways to run away from the world that he did not have courage to face. Being caught in painful memories in the Bombing of Dresden, Billy could only relieve himself from misery through a time travel to escape from death and war.

Generally speaking, Celestial city is to Christian as Tralfamadore is to Billy. What's different is that Christian searched a way to celestial city for his belief to god, but Vonnegut escaped to a fictional planet from violence and war because he lost his belief. Christian sublimated his personality with the persistent pursuit of belief. Ironically, Billy suffered from mental dissociation, losing his bearings in time travel. All in all, seemingly clumsy imitative writing masterly discloses Vonnegut's despair to survive in earth for relentless war.

\section{B. Adam and Eve in Eden: Billy and Montana in Tralfamadore}

Imageries of Adam and Eve frequently emerge in Slaughterhouse-Five. As the novel described that "He said, too, that he had been kidnapped by a flying saucer in 1967. The saucer was from the planet Tralfamadore, he said. He was taken to Tralfamadore, where he was displayed naked in a zoo, he said. He was mated there with a former Earthling movie star named Montana Wildhack" (Vonnegut, 1969, p.12). The author directly depicted that Billy imaged Tralfamadore as an Eden without war and evil. In addition, William Rodney also said, "Billy and Montana are the newborn Adam and Eve in a perfect world" (Vonnegut, 1991, p.93). Therefore, readers might dauntlessly guess that Tralfamadore perhaps is the Eden in the Bible. Nevertheless, the author declared unexpectedly, "On Tralfamadore, says Billy Pilgrim, there isn't much interest in Jesus Christ. The Earthling figure who is most engaging to the Tralfamadorian mind, he says, is Charles Darwin-who taught that those who die are meant to die, that corpses are improvements. So it goes" (Vonnegut, 1969, p.93) in the last chapter. So readers suddenly realize that Tralfamadorian is not the Eden in the Bible; Billy and Montana are not Adam and Eve. 
Images of Adam and Eve are specialized in Slaughterhouse-Five, different form original figures in the Bible. The description of Adam and Eve was that "If you look in there deeply enough, you'll see Adam and Eve. Billy Pilgrim had not heard this anecdote. But, lying on the black ice there, Billy stared into the patina of the corporal's boots, saw Adam and Eve in the golden depths" (Vonnegut, 1969, p.24) in Slaughterhouse-Five. Vonnegut deconstructed them, and then reinvented them, so that he could produce dramatic absurdity and inexplicability. For Vonnegut, the whole world is distorted and irrational. Therefore, there is a need to destroy the old planet, rebuilding a new "Eden".

In a word, Vonnegut never believed that any religion could help people to solve problems. He employed parodies to deconstruct the Bible's stories to express his anti-God, anti-Christianity, as well as other traditional religions after the Second World War. "Strong faiths in the past turn out to be painful doubts...literary descriptions of Christianity are usually slapstick or comedy", Reed, Peter J. Ed. described (Reed, 1996, pp.145-146).

\section{Jesus' Prediction of Death: Billy's Prophesy Related to Death}

In Slaughterhouse-Five, Vonnegut parodies Jesus Christ too. Allen used to say in her book, "Actually this vulnerable and miserable Billy Pilgrim is newborn Jesus in the novel" (Allen, 1991, p. 87). As Jesus was mocked by soldiers and passersby, Billy was laughed at by his comrade-in-arms during the war. Another important point was that Billy bore a striking resemblance to Jesus' death.

Billy knew exactly the time when he died and the killer who murdered him, as the novel showed, "Billy predicts his own death within an hour.... He is an old man now, living not far from here" (Vonnegut, 1969, pp.63-64). Billy even recorded a piece of word that "I, Billy Pilgrim, the tape begins, will die, have died and always will die on February thirteenth, 1976" (Vonnegut, 1969, p.63) to witness his death. Those words reminded readers that Jesus told his followers he knew who was murderer in the Last Supper. Similarly, the author narrated, "Early in 1968, a group of optometrists...the plane crashed on top of Sugarbush Mountain, in Vermont. Everybody was killed but Billy" (Vonnegut, 1969, p.12). After crash, Billy seemingly experienced a new born. In the Bible, the king slaughtered all the children below two years old in order to kill Jesus in Bethlehem. Jesus, like Billy, was also the only one who escaped from death. To some extent, Billy and Jesus obviously overlap.

However, when readers approve the identity's consistency of Billy and Jesus, Vonnegut overthrew the consistency. Billy was like a lifeless puppet, an anti-hero in the postmodern society. Billy was described as a new "Christian" who was controlled and contorted by external pressure. Moreover, Jesus' death was a sacrifice. However, Billy's death valued nothing. Though Billy preached some new concepts about time and life which learnt from Tralfamadorian to attempt to change people's opinions about their life, it was in vain. What Billy acquired in Tralfamadorian was negative acceptance or evasion to death. Because all the difficulties could explain in one sentence-so it goes.

Therefore, Vonnegut tactfully and vaguely criticizes religions by a parodied Jesus - Billy. This kind of parody makes readers realize that human beings have already lost their confidence to religions in this ridiculous and chaotic world. Because none of religion could provide a way to mitigate their spiritual pressure and creates a forever peaceful spiritual home. As for Vonnegut, Jesus Christ is helpless, as well as preposterous. To some extent, the loss of spiritual ballast makes postmodern people be immersed in belief crisis. However, the crisis is caused by tenterhooks to the turbulent times and the chaotic social order.

\section{CONCLUSIONS}

In a sense, narrative methods compose a basic framework of a novel. Metafiction is a characteristic narrative technique in the postmodern literature. It plays an important part in the postmodern novels. Vonnegut skillfully wielded metafiction in Slaughterhouse-Five to convey its anti-war theme to the extreme. Vonnegut made a breakthrough in metafiction, endowing it with features of non-linear narrative, collage and parody. His narrative techniques overturn traditional novels' narrative structure.

Firstly, the application of the abnormal narrative methods was caused by his mental trauma or his psychological illness after the Second World War. Although Vonnegut tried to recollect memories of war, he could not recall them well-organized and logically. Hence non-linear narrative emerges in Slaughterhouse-Five. Tangled time-space view interprets massacre of Dresden cast its shadow to Billy and Vonnegut. Transformations of person make the novel waver between the reality and imagination. Secondly various materials of collages make contrasts among diverse accounts for the firebombing of Dresden. On one hand, citations of official sources and other works expose war's darkness and brutality in a serious way. On the other hand, folk cultures' quotation alleviates repression, comically revealing helplessness and despair to death. Finally, by virtue of parodies, Vonnegut criticized that religion could not assist mankind in shuffling off this mortal coil to express his loss of faith, and he revealed that people were caught into spiritual wasteland in the postmodern society. All in all, every method employed in Slaughterhouse-Five reveals the detestation to war and the desperation to survival consciously.

Based on the above information, no matter what narrative techniques adopted by Vonnegut, his purpose was to expose the theme of loss of humanity and hatred to wars. Frequent occurrence of "so it goes" also accurately reaches his purpose. At the time Vonnegut turned up in the novel as a narrator, the narrator talked about Billy's life before, during and after the war, as well as his life on Tralfamadore. Vonnegut described objectively and naturally several stages of Billy without any extra personal opinions. It makes reader feel the author's indifference and insouciance immediately. 
Comrade-in-arms died; parents died; big bugs died; 135000 people died. Deaths were common things in the novel. Vonnegut used one sentence to response every death, "So it goes". It arose in the novel almost one hundred times. "So it goes" gradually became the symbol of death. This is the highlight of the author's black humor. It also made a contrast between the author's unconcerned statement and the story's cruel situation. Vonnegut did not give his opinion directly, but his abnormal reaction had already testified his attitude towards wars. It is no need to justify a war. Vonnegut told a miserable story about a survivor's postwar life in the perspective of a bystander, so that it could alleviate his pain. The appearance of "So it goes" fully reflected the author's helplessness and irony to reality, and reveal the novel's themesloss of humanity and hatred to wars.

\section{REFERENCES}

[1] Allen, William Rodney. (1991). Understanding Kurt Vonnegut. Columbia: The University of South Carolina Press.

[2] Broer, Lawrence R. (1994). Sanity Plea: Schizophrenia in the Novels of Kurt Vonnegut. Alabama: University of Alabama Press.

[3] Dentith, Simon. (2001). Parody. London: Routledge Press.

[4] Genette, G., Ben-Ari, N., \& Mchale, B. (1990). "Fictional narrative, factual narrative.” Poetics Today, 11(4), 755-774.

[5] Isaacs, Neil D. (1973). “Unstuck. In: Time: 'Clockwork Orange' and 'Slaughterhouse-Five'.” Literature/Film Quarterly No. 2 , Vol. 1.

[6] Lundquist, James. (1976). Kurt Vonnegut. New York: Ungar.

[7] Reed, Peter J. (ed) (1996). The Vonnegut Chronicles: Interviews and Essays. West-port, CT: Greenwood Press.

[8] Scholes, Robert.(1979). Fabulation and Metafiction. Urbana: University of Illinois Press.

[9] The Oxford English Dictionary. (1989). Oxford: Clarendon Press.

[10] Vonnegut, Kurt JR. (1981). Palm Sunday. New York: Delacorte Press.

[11] Vonnegut, Kurt JR. (1969). Slaughterhouse-Five. New York: The Bantam Doubleday \& Dell Publishing Group, Inc.

[12] Waugh, Patricia. (1984). Metafiction: The Theory and Practice of Self - Conscious Fiction. London and New York: Methuen.

[13] Whitehead, Anne. (2004). Trauma Fiction. Edinburgh: Edinburgh University Press.

[14] Xie, Yu. (2009). A Utopian Pilgrimage through Fragmented World: A Thematic Analysis of Slaughterhouse-Five. Unpublished MA thesis, Shandong University of Science and Technology.

Jing Shi is currently a PhD candidate of English literature in Shanghai International Studies University, Shanghai, China. She is also a lecturer in shanghai Institute of Technology, Shanghai, China. She received her master's degree of Arts in Shanghai University, China in 2017. Her research interest includes American literature and British literature. 